\title{
Polymer Electrolyte Fuel Cells Employing
}

\section{Heteropolyacids as Redox Mediators for Oxygen}

\section{Reduction Reactions: Pt-Free Cathode Systems}

Toshiaki Matsui, ${ }^{*}{ }^{\dagger}$ Eri Morikawa, ${ }^{\dagger}$ Shintaro Nakada, ${ }^{\dagger}$ Takeou Okanishi, $^{\dagger}$ Hiroki Muroyama, ${ }^{\dagger}$ Yoshifumi Hirao, ${ }^{\dagger}$ Tsuyoshi Takahashi, ${ }^{\ddagger}$ and Koichi Eguchi*, ${ }^{\dagger}$

${ }^{\dagger}$ Department of Energy and Hydrocarbon Chemistry, Graduate School of Engineering, Kyoto University, Nishikyo-ku, Kyoto 615-8510, Japan.

* Higashifuji Technical Center, TOYOTA Motor Corporation, Mishuku, Susono, Shizuoka 410-1193, Japan

\section{Corresponding Authors}

*Toshiaki Matsui

TEL: +81-75-383-7060, FAX: +81-75-383-2520

E-mail: matsui@elech.kuic.kyoto-u.ac.jp

*Koichi Eguchi

E-mail: eguchi@scl.kyoto-u.ac.jp 


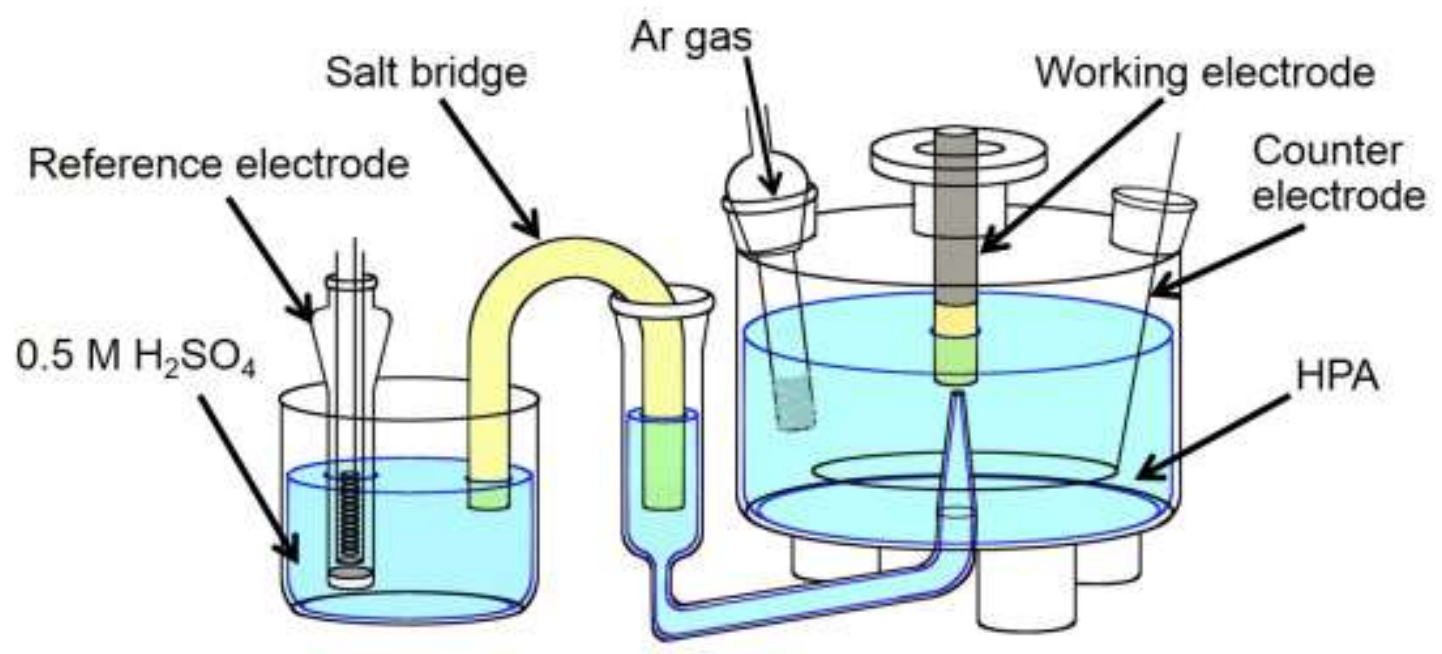

Figure S1. Schematic illustration of experimental setup of a three-electrode cell. 

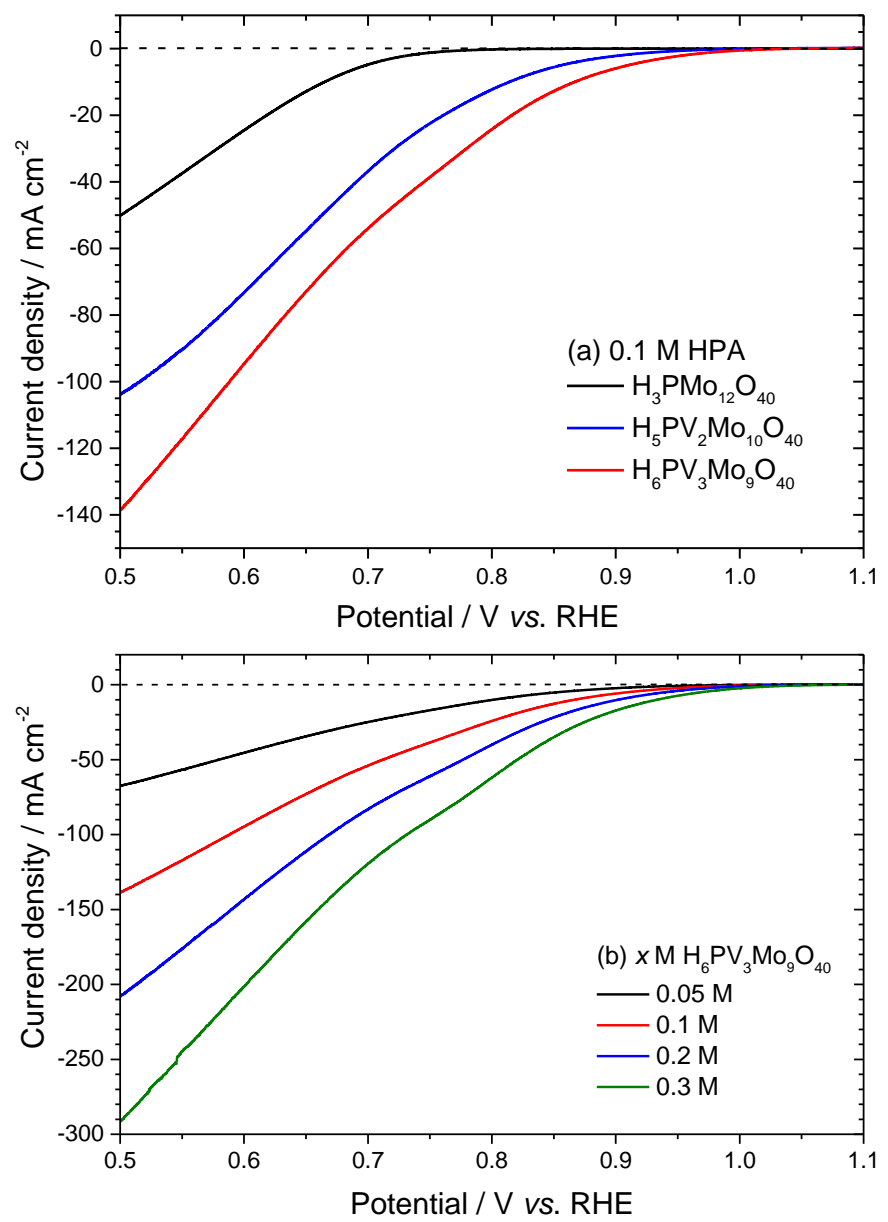

Figure S2. Linear sweep voltammograms of the GC disk electrode at $80{ }^{\circ} \mathrm{C}$ with a scanning rate of $1 \mathrm{mV} \mathrm{s}^{-1}$ in (a) $0.1 \mathrm{M} \mathrm{HPA}$ (HPA: $\mathrm{H}_{3} \mathrm{PMo}_{12} \mathrm{O}_{40}, \mathrm{H}_{5} \mathrm{PV}_{2} \mathrm{Mo}_{10} \mathrm{O}_{40}$, or $\left.\mathrm{H}_{6} \mathrm{PV}_{3} \mathrm{Mog}_{9} \mathrm{O}_{40}\right)$ and (b) $x \mathrm{M} \mathrm{H}_{6} \mathrm{PV}_{3} \mathrm{Mo}_{9} \mathrm{O}_{40}(x=0.05 \sim 0.3 \mathrm{M})$. Rotation rate of glassy carbon electrode: $1000 \mathrm{rpm}$. 


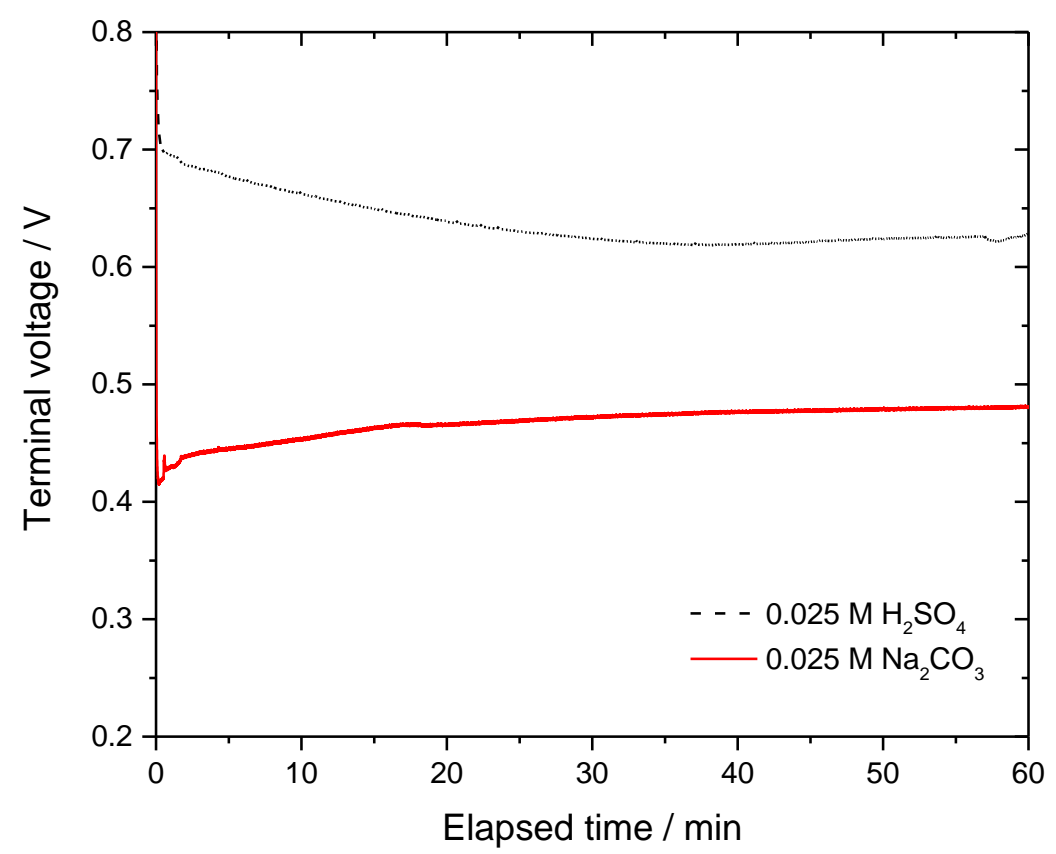

Figure S3. Time course of terminal voltage of PEFC at a current density of $5.36 \mathrm{~mA}$ $\mathrm{cm}^{-2}$. Operating temperature: $80{ }^{\circ} \mathrm{C}$, catholyte: $0.01 \mathrm{M} \mathrm{H}_{6} \mathrm{PV}_{3} \mathrm{Mo}_{9} \mathrm{O}_{40}$ added with 0.025 $\mathrm{M} \mathrm{H}_{2} \mathrm{SO}_{4}$ or $\mathrm{Na}_{2} \mathrm{CO}_{3}$ aqueous solutions, anode gas: $\mathrm{H}_{2}$ (RH 100\%), gas supplied to HPA: $\mathrm{O}_{2}$. 